\title{
Sepsis in Acute Mediastinitis - A Severe Complication after Oesophageal Perforations. A Review of the Literature
}

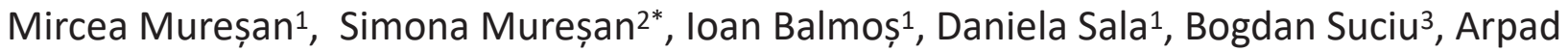 \\ Torok $^{1}$ \\ 1 University of Medicine, Pharmacy, Science and Technology of Târgu Mureș, Surgery Clinic No.2 \\ 2 University of Medicine, Pharmacy, Science and Technology of Târgu Mureș, Physiology Department \\ 3 University of Medicine, Pharmacy, Science and Technology of Târgu Mureș, Thoracic Surgery Department
}

\begin{abstract}
Background. Despite recent advancements in antibiotic therapy and the progress made in critical care and modern diagnostic methods, acute mediastinitis continues to be a severe condition.

Diagnosis and treatment. Acute mediastinitis can occur in the context of cardio-thoracic surgery, oesophageal perforations and oropharyngeal infections condition. Forty-five percent of oesophageal perforations occurs during simple endoscopy. Spontaneous perforation (Boerhaave syndrome) accounts for $15 \%$ of perforations, and twelve percent are due to the ingestion of foreign bodies. Other causes include blind or penetrating trauma, and circa $9 \%$ to intraoperative lesions. CT scan is the standard investigation that reveals direct signs of mediastinitis.

The oral administration of contrast substances can underscore the level of oesophageal perforation. Conservative treatment is the first-choice treatment and surgical treatment is reserved only for specific situations.

The principles of surgical treatment consist of drainage, primary suture, oesophageal exclusion with or without the application of oesophagectomy, endoscopic vacuum wound assisted therapy of the perforation and associated paraoesophageal mediastinal drainage and endoscopic stenting associated with drainage.

Conclusions. The lowest mortality rate is recorded in patients with perforations diagnosed less than twenty-four hours after the onset of symptoms. Surgical treatment remains the gold standard especially in cases of thoracic and abdominal perforations while further investigations are mandatory before endoscopic stenting is carried out.
\end{abstract}

Keywords: Acute mediastinitis, oesophageal perforation, Boerhaave syndrome

Received: 12 March 2019 / Accepted: 23 April 2019

\section{BACKGROUND}

Despite recent advancements in antibiotic therapy and the progress made in critical care and modern diagnostic methods, acute mediastinitis continues to be a severe condition with a high mortality rate [1]. Its intrathoracic position in an anatomically closed space comprising well-vascularized adipose tissues and the proximity of vital organs, makes this disease an important clinical issue. Frequently there is a rapid evolution of the disease resulting in multisystem organ failure (MSOF) and sepsis[2]. The disruption of the aetiopathogenic chain sometimes requires an oesophagectomy, which when performed in an already profoundly affected area, may cause death[2]. The crucial element to improve prognosis is early diagnosis and the application of therapeutic measures within twenty-four hours after the onset of symptoms [3].

\section{EPIDEMIOLOGY}

The global mortality rate is between $19-47 \%$ [4], with differences influenced by the aetiology of the disease. Thus, Rieder (2010) reports a mortality rate of $11-34 \%$ for descending necrotising mediastinitis of oropharyngeal infections, but in case of associated comorbidities, 
this rate increases to $67 \%$ [4]. Both genders are reported to suffer from this disease, but males are more often affected, at a ratio of $6: 1[4,5]$. Although the literature gives an account of exceptions, most cases of acute mediastinitis occur in the third, fourth, and fifth decades of life. The influence of age on the mortality rate has been substantiated with experimental data, with minor differences in the first two decades, but these differences become evident after the fifth decade of life[5]. Studies performed on large groups of patients report different but consistently high mortality rate (Table 1 ).

Acute mediastinitis can also occur in the context of cardio-thoracic surgery such as emergency interventions, prolonged operative or cardiopulmonary bypass time, bilateral internal mammary artery grafting, the complexity of procedures, the use of intra-aortic balloon pumps, lack of adequate antibiotic prophylaxis [10], as well as oesophageal perforations, and oropharyngeal infections such as para-pharyngeal abscess and odontoid process with epidural abscess of a descending necrotizing nature [11]. These triggering conditions are more aggressive if associated with factors such as age, smoking, chronic pulmonary disease, diabetes mellitus, chronic kidney failure, immunosuppression treatment with corticosteroids, and generalised atherosclerosis [12].

Sixty to sixty-four percent of acute mediastinitis is triggered by complications after cardiac operations [4, 12]. Oesophageal perforation account for $25-31 \%$ of cases and is the second most occurring cause of mediastinitis, with the remaining cases being caused by oropharyngeal infections [13].

Oesophageal perforation generally occurs in areas of physiologic narrowing, for example, in the cricopharyngeal muscle or oesophagogastric junction. Most oesophageal perforations are iatrogenic (50-75\%) and most of them occur during endoscopic procedures $[14,15]$. The incidence of perforation in case of simple endoscopy is $<0.5 \%$ but may increase to $6 \%$ in the

Table 1. The mortality rate of acute mediastinitis reported in different studies [6-9]

\begin{tabular}{lccc} 
Author/s & Year & $\begin{array}{c}\text { Number of } \\
\text { cases }\end{array}$ & $\begin{array}{c}\text { Mortality } \\
\text { rate }\end{array}$ \\
\hline Cherveniakov & 1992 & 147 & $14,4 \%$ \\
Marty-Ane et al & 1999 & 12 & $16,5 \%$ \\
Papalia et al & 2001 & 13 & $23 \%$ \\
Macrí P et al & 2003 & 26 & $15,4 \%$ \\
Vidarsdottir et al & 2010 & 29 & $31 \%$ \\
\hline
\end{tabular}

case of endoscope-guided pneumatic dilation to treat achalasia [16]. Rigid oesophagoscopy, currently less commonly used, is associated with an increased risk of perforation [17]. Spontaneous perforation (Boerhaave syndrome) represents $15 \%$ of perforations which are usually located at the level of the distal supra-cardiac oesophagus, the left flank often being more affected. The ingestion of foreign bodies represents approximately $12 \%$ of oesophageal perforations, being more common at the level of the cricopharyngeus muscle [18]. Other causes of oesophageal perforations include trauma, cica 9\% [16], and intraoperative lesions, $2 \%$ $[19,20]$,

Thoracic and abdominal surgery [21], and malignant lesions account for about $1 \%$ of cases [22].

The aetiology and localisation of perforation significantly affect mortality. The highest mortality rate, $36 \%$ in case of spontaneous oesophageal perforation, is probably accounted for due to a late diagnosis [3]. Traumatic perforations are usually detected early and are most commonly associated with lesions associated with cricopharyngeal narrowing at the level of the upper oesophageal sphincter, with a mortality rate of less than $7 \%$. Regarding anatomical locations, cervical oesophageal perforations have the lowest mortality rate of $6 \%$, while thoracic and abdominal perforations have significantly higher mortality rates at $27 \%$ and $21 \%$, respectively [14].

\section{Clinical Manifestation of Acute MEDIASTINITIS}

The clinical manifestations of acute mediastinitis are augmented by an up-to-date medical history. Thus, patients can give account on digestive endoscopy or swallowing foreign bodies, and in the case of Boerhaave syndrome, chronic alcoholism is often present. According to Schmidt (2010), the main symptoms and their frequency are dysphagia (80.6\%), retrosternal pain with interscapular irradiation in the shoulders or throat $(56.5 \%)$, nausea and vomiting (50\%), fever and chills (38.7\%), dyspnoea (19.4\%), and confusion (15.5\%) [23].

Clinical examination usually reveals tachypnoea, tachycardia, oedema of the face and neck, subcutaneous emphysema located at the level of the thorax and cervix, and Hamman's sign with crunching sounds on auscultation of the heart $[23,24]$. 
Abbas et al. (2009) introduced a clinical perforation severity score that could be correlated with mortality rate[25]. (Table 2)

Thus, in a total of 119 cases, when $n$ score $<2$ the mortality rate was $2 \%$, when $n$ score $=3$ or 4 the mortality rate was $6 \%$, and when $n$ score $>5$ the mortality rate increased drastically to $26 \%$. At values of $n$ score higher than 8 , mortality was over $85 \%$, and $n$ score $>10$ was associated with $100 \%$ mortality [25].

\section{MICROBIOLOGY OF MEDIASTINAL}

\section{INFECTION}

The most frequently implicated microorganisms are bacteria from the initial stage of microbial colonization in the upper gastrointestinal tract (Table 3), subsequently due to the worsening of the general condition and decreasing immunity, the patient becomes vulnerable to associated aggressive infections by developing sepsis with severe manifestations, MSOF, and primary or secondary abdominal compartment syndrome [2628].

Paraclinical diagnosis is not specific for acute mediastinitis, since it determines leukocytosis, respectively

Table 2. Prognostic score for mortality in case of mediastinitis due to oesophageal perforation

\begin{tabular}{ll} 
Points & Sign and symptoms \\
$\begin{array}{ll}\text { One point for each of } \\
\text { the following }\end{array}$ & $\begin{array}{l}\text { Age }>75 \text { years } \\
\text { Tachycardia } \\
\text { Leukocytosis } \\
\text { Pleural effusions }\end{array}$ \\
\hline Two points for each of & Fever \\
the following & Noncontained leak on barium \\
& $\begin{array}{l}\text { esophagram } \\
\text { Respiratory compromise }\end{array}$ \\
& Time to diagnosis $>24 \mathrm{~h}$ \\
\hline Three points for each of & $\begin{array}{l}\text { Presence of malignancy } \\
\text { the following }\end{array}$ \\
\hline
\end{tabular}

increased inflammatory markers (C-reactive protein, $\mathrm{VSH}$, procalcitonin), which can cause blood sugar imbalances and hyponatremia. It is essential to collect blood culture as early as possible [29, 30].

Conventional thoracic radiography can highlight the indirect signs of mediastinitis such as subcutaneous emphysema, lateral or anterior tracheal deviation, and pleural fluid collections $[4,31]$.

The level of perforation can be approximated by radiologic evaluation using a small quantity of low-osmolar water-soluble contrast media, but per oral contrast can be a potentially aggravating factor of the disease. Computerized Tomography (CT) should be the backup solution [32], which is also a useful investigative method in monitor the effectiveness of endoscopic or surgical treatment (Figure 1).

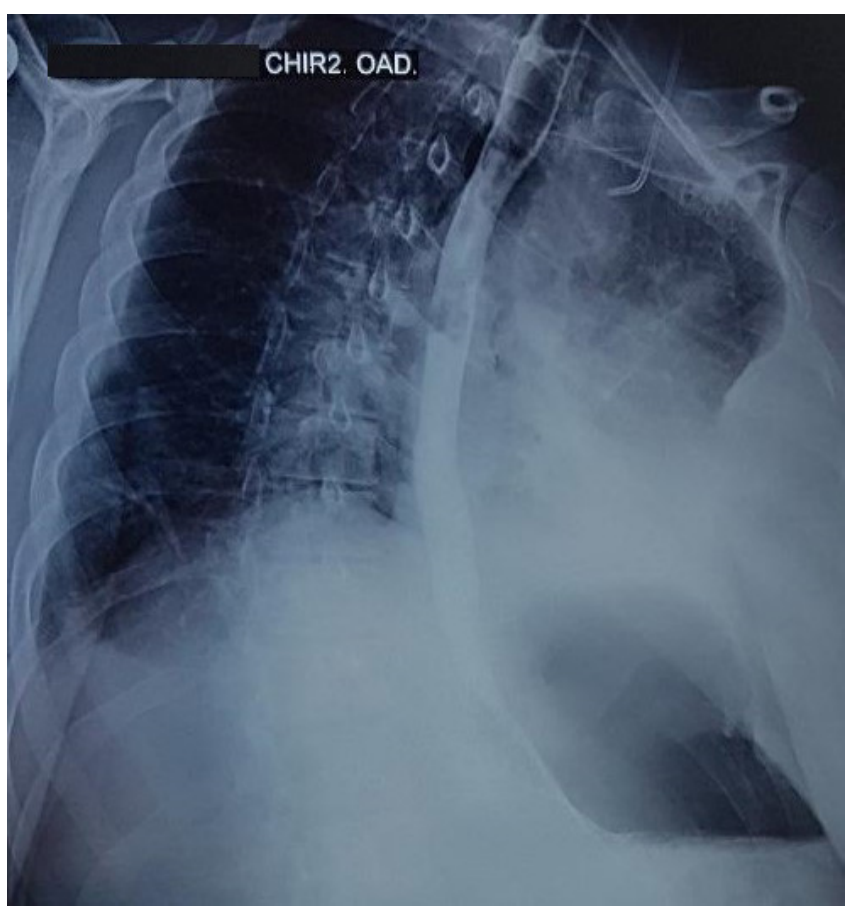

Fig. 1. Lateral chest radiography with contrast: no signs of oesophageal fistula ten days after surgery (personal database)

Table 3. Microorganisms involved in the aetiology of acute mediastinitis due to oesophageal perforations [27-28]

\begin{tabular}{|c|c|c|c|c|}
\hline Germs & Gram-positive cocci & Gram-positive bacilli & Gram-negative cocci & Gram-negative bacilli \\
\hline Anaerobic & Peptostreptococcus & $\begin{array}{c}\text { Actinomyces Lactobacillus } \\
\text { Eubacterium }\end{array}$ & Veillonella & $\begin{array}{l}\text { Bacteroides } \\
\text { Prevotella } \\
\text { Porphyromonas } \\
\text { Fusobacterium }\end{array}$ \\
\hline Aerobic & $\begin{array}{l}\text { Streptococci (including } \\
\text { beta-hemolytic and S. } \\
\text { viridans group), } \\
\text { Staphylococci }\end{array}$ & Corynebacterium & Moraxella & $\begin{array}{c}\text { Enterobacteriaceae } \\
\text { Eikenella corrodens } \\
\text { Pseudomonas }\end{array}$ \\
\hline Fungi & Candida albicans & & & \\
\hline
\end{tabular}


A CT scan is the standard investigation that reveals direct signs of mediastinitis, mediastinal soft tissue congestion and pneumomediastinum [33]. Furthermore, the oral administration of contrast substances can highlight the level of oesophageal perforation, which is extremely important in the choice of subsequent medical and surgical therapeutic therapy. Additionally, CT scanning helps to investigate the pleural

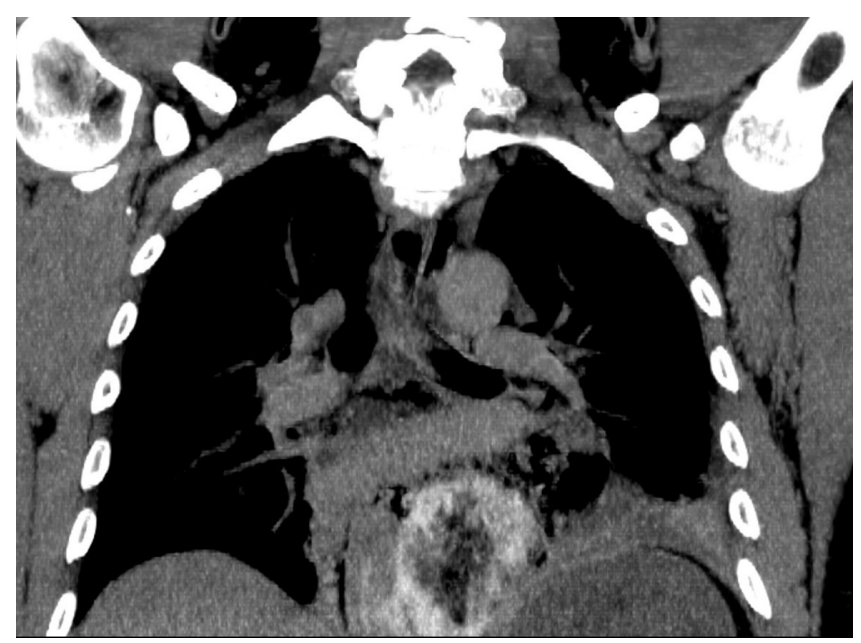

Fig. 2. CT scan with oral contrast: frontal reconstruction. Oesophageal perforation located above the diaphragm with mediastinitis and pleural effusion on the left side. (personal database) cavities and can indicate the cause of the perforation $[34,35]$. (Figure 2)

Nuclear magnetic resonance (NMR) provides an alternative for children, but it does not offer some of the additional information obtained with CT scans [34].

An upper gastrointestinal (GI) endoscopy is performed only in particular cases, having both a diagnostic and curative role, such as the placement of an endooesophageal prosthesis to cover a fistula [36].

In cases of inferior oesophageal fistula following sleeve gastrectomy for morbid obesity, it represents the first option of treatment [37].

\section{TREATMENT OF ACUTE MEDIASTINITIS}

The complexity of the disease due to the level of perforation, aetiology, and complications requires different treatment modalities. While conservative treatment is mandatory, surgical treatment is reserved only for specific situations [38]. (Figure 3)

When oesophageal perforation is suspected, dietary intake and oral hydration are discontinued, and broad-spectrum antibiotic therapy is initiated to prevent infections usually caused by Gram-positive, gramnegative, and anaerobic microorganisms. Antifungal

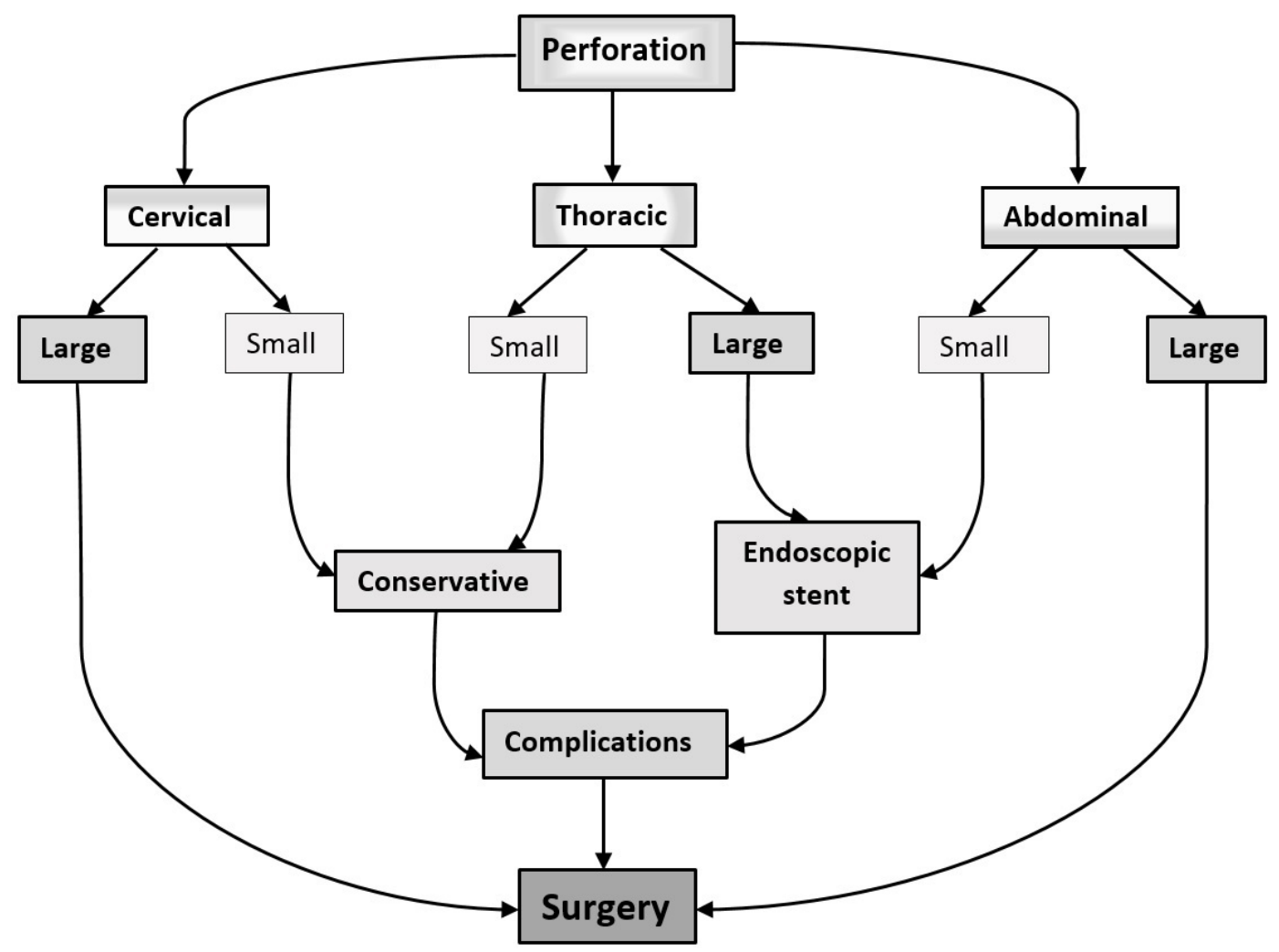

Fig. 3. Surgical and endoscopic treatment indication according to location and perforation size. 
agents are normally prescribed to immunosuppressed patients. Blood culture results will indicate appropriate antibiotic therapy $[29,38]$.

Intravenous (IV) administration of proton pump inhibitors (PPIs) reduces gastric acidity and gastroesophageal reflux, thus avoiding the association of a chemical component to bacterial mediastinitis $[36,38]$.

In addition to these approaches, the non-specific measures of conservative treatment will include haemodynamic resuscitation, restoration of the hydroelectrolyte balance, diabetes control, tachycardia control, and the control of hypotension using vasoactive agents [36].

Surgical treatment is reserved mainly for thoracic and abdominal perforations, while in case of the involvement of the cervical plexus, the first-choice treatment is a conservative one associated with drainage [38].

The principles of surgical treatment consist of drainage, primary suture, oesophageal exclusion with or without oesophagectomy, endoscopic vacuum woundassisted therapy of the perforation and associated para-oesophageal mediastinal drainage and endoscopic stenting associated with drainage [22, 35, 38-41].

The main indications of these surgical methods are listed in Table 4.

\section{口iscussions}

Although the mortality rate in acute mediastinitis remains high, new diagnostic imaging methods have led to a reduction in the time required for the diagnosis of oesophageal perforation, significantly improving prognosis [3]. Multicentric studies have demonstrated that whenever oesophageal perforation is suited to suturing, postoperative outcomes are superior. Thus, in the case of Boerhaave syndrome, iatrogenic perforations or foreign body ingestion, if the perforation is identified early, viable and regular margins of the perforation lead to a higher surgical healing rate [42].

Among the surgical methods, primary suture is the treatment of choice with the best postoperative results [43]. Location is an essential element. While in the case of cervical perforation, surgical and endoscopic therapeutic options are extremely low, in thoracic and abdominal ones, primary suturing and endoscopic stenting of the perforation significantly improve survival rate [42].

Late perforations and oesophageal neoplasm require difficult surgical treatment with oesophageal stripping, oesophagostomy and gastrostomy, followed by oesophageal reconstruction after 6-12 months. The evolution

Table 4. Surgical and endoscopic treatment: indications, class of evidence and recommendations

\begin{tabular}{|c|c|c|}
\hline $\begin{array}{l}\text { Surgical treatment of } \\
\text { oesophageal perforations }\end{array}$ & Recommended & $\begin{array}{l}\text { Class of } \\
\text { evidence* }\end{array}$ \\
\hline Primary repair & $\begin{array}{c}\text { Perforation }<24 \mathrm{~h} \\
\text { Perforation }<72 \mathrm{~h} \\
\text { Thoracic small perforation (failure off medical treatment) } \\
\text { Abdominal perforations }<24 \mathrm{~h}\end{array}$ & $\begin{array}{l}\text { IA } \\
\text { IC } \\
N^{* *} \\
\text { IA }\end{array}$ \\
\hline Drainage only & $\begin{array}{c}\text { Cervical perforations } \\
\text { Thoracic small perforations }\end{array}$ & $\begin{array}{l}\mathrm{IIC} \\
\mathrm{NA}\end{array}$ \\
\hline $\begin{array}{l}\text { Diversion without esopha- } \\
\text { gectomy }\end{array}$ & $\begin{array}{l}\text { Severe mediastinitis after large thoracic perforations in critical patient } \\
\text { Advance stages of oesophageal cancer perforations }\end{array}$ & IIC \\
\hline Esophagectomy & $\begin{array}{l}\text { Severe mediastinitis after large thoracic perforations if general condi- } \\
\text { tions allow } \\
\text { Initially stages of oesophageal cancer }\end{array}$ & IIC \\
\hline $\begin{array}{l}\text { Endoscopic vacuum-assisted } \\
\text { closure system (E-VAC) }\end{array}$ & Large perforations with an efficient peri-oesophageal drainage & IIC \\
\hline $\begin{array}{l}\text { Oesophageal stenting associ- } \\
\text { ated with pleural/mediastinal } \\
\text { drainage }\end{array}$ & $\begin{array}{c}\text { Thoracic perforations }<24 \mathrm{~h} \text { in stable patients } \\
\text { Bridging method for critical patients }\end{array}$ & $\| \mathrm{C}$ \\
\hline $\begin{array}{l}\text { Class of evidence and recommendations: } \\
\text { evels: } \\
\text { - High-quality prospective cohort study with adequat } \\
\text { I- Lesser quality prospective cohort, retrospective co } \\
\text { S-ade Practice Recommendations } \\
\text { - Strong recommendation; B- Recommendation; C- C } \\
\text { *NA - Not available }\end{array}$ & $\begin{array}{l}\text { ower or systematic review of these studies } \\
\text { t study, untreated controls from a randomised control trials (RCT) point of view, or systematic review of these studies } \\
\text { on }\end{array}$ & \\
\hline
\end{tabular}


of these cases is in most cases unfavourable, due to the progression of mediastinitis and the development of septic shock [27].

Conservative treatment remains the primary therapy of any indifferent oesophageal perforation no matter if is followed by surgical or endoscopic treatment. In a retrospective study of fifty-seven patients, the development of supportive treatment methods from intensive care units and the introduction of new generations of antibiotics improved prognosis by at least 10\% [44].

\section{- CONCLUSIONS}

Oesophageal perforations remain a diagnostic and therapeutic challenge. The lowest mortality rate was recorded in patients with perforations diagnosed less than 24 hours after the onset of the symptoms, this period being the critical issue predicating therapeutic success.

When surgical treatment is feasible, for cases of thoracic and abdominal perforations, there are good postoperative results and higher survival rates. This situation has not changed significantly over the past two decades. The improvement of prognosis and decrease in mortality rate is due to antibiotic therapy and advances in critical care.

The use of oesophageal stenting is still under debate. Regardless of the choice of treatment, oesophageal perforation remains a severe surgical problem because of the rapid health decline, and therefore, all cases should be administered by a team of thoracic surgeons.

\section{- CONFLICT OF INTEREST}

Authors declare no conflict of interests.

\section{REFERENCES}

1. Risnes, I, Abdelnoor M, AlmdahI SM, Svennevig JL. Mediastinitis after coronary artery bypass grafting risk factors and long-term survival. Ann Thorac Surg. 2010;89:1502-9.

2. Biancari F, D'Andrea $V$, Paone $R$ et al. Current treatment and outcome of oesophageal perforations in adults: systematic review and meta-analysis of 75 studies. World J Surg. 2013;37:1051-9.

3. Shaker $H$, Elsayed $H$, Whittle I, Hussein S, Shackcloth $M$. The influence of the 'golden 24-h rule' on the prognosis of oesophageal perforation in the modern era. Eur J Cardiothorac Surg. 2010;38:216.
4. Ridder GJ, Maier W, Kinzer S, Teszler CB, Boedeker CC, Pfeiffer $J$ J. Descending necrotising mediastinitis: contemporary trends in aetiology, diagnosis, management, and outcome. Ann Surg. 2010;251(3):528-34.

5. Papakonstantinou NA, Patris V, Antonopoulos CN, Samiotis I, Argiriou M. Oesophageal necrosis after thoracic endovascular aortic repair: a minimally invasive endovascular approach-a dramatic complication. Interact Cardiovasc Thorac Surg. 2019;28(1):9-16.

6. Cherveniakov, A and Cherveniakov, P. Surgical treatment of acute purulent mediastinitis. Eur J Cardiothorac Surg. 1992;6:407-11.

7. Papalia E, Rena O, Oliaro A, et al. Descending necrotising mediastinitis: surgical management. Eur J Cardiothorac Surg. 2001;20:739-42.

8. Macrí P, Jimenez MF, Novoa NV, Gonzalo V. A descriptive analysis of a series of patients diagnosed with acute mediastinitis. Archivos de bronconeumología 2003;9:428-30.

9. Vidarsdottir $H$, Blondal $S$, Alfredsson $H$, Geirsson A, Gudbjartsson T. Oesophageal perforations in Iceland: a whole population study on incidence, aetiology and surgical outcome. Thorac Cardiovasc Surg. 2010; 58(8):476-80.

10. Graf K, Ott E, Vonberg RP, Kuehn C, Haverich Chamberny IF. Economic aspects of deep sternal wound infections. Eur J Cardiothorac Surg. 2010;37:893-896.

11. Razafimanjato NNM, Ralaizafindraibe TH, Ramarolahy $A R$, Rajaonera TA, Rakotovao HJL. Acute descending necrotising mediastinitis: four years of experience at a hospital centre in Madagascar. Med Sante Trop. 2018;28(3):297-301.

12. Salehi Omran A, Karimi A, Ahmadi SH et al. Superficial and deep sternal wound infection after more than 9000 coronary artery bypass graft ( $C A B G)$ : incidence, risk factors and mortality. BMC Infect Dis. 2007;7:112.

13. Petitpas F, Blancal JP, Mateo J et al. Factors associated with the mediastinal spread of cervical necrotising fasciitis. Ann Thorac Surg. 2012; 93:234-8.

14. Brinster CJ, Singhal S, Lee L, Marshall MB, Kaiser LR, Kucharczuk JC. Evolving options in the management of oesophageal perforation. Ann Thorac Surg. 2004;77:1475.

15. Almorza T, Herrera-Juárez M, Lalueza A. Spontaneous mediastinitis with multiple oesophageal abscess in the esophagus. Respir Med Case Rep. 2018;25:196-198.

16. Chirica M, Champault A, Dray X, et al. Esophageal perforations. J Visc Surg 2010;147:e117-28

17. Ryom P, Ravn JB, Penninga $L$ et al. Etiology, treatment and mortality after esophageal perforation in Denmark. Dan Med Bul. 2011;58:A4267

18. Tullavardhana T. latrogenic Esophageal Perforation. J Med Assoc Thai. 2015;98(Suppl 9):S177-83.

19. Neagoe RM, Mureșan M, Voidăzan S, Pașcanu I, Radu CP, Sala DT. Subtotal parathyroidectomy versus total parathyroidectomy with autotransplant in secondary hyperparathyroidism - a single-centre prospective cohort of 43 patients. Endokrinologia 
Available online at: www.jccm.ro

Polska. 2016;67(2):202-9.

20. Neagoe RM, Cvasciuc IT, Muresan M, Sala DT. Incidental parathyroidectomy during thyroid surgery- risk, prevention and controversies; a review. Acta Endo (Buc). 2017;13(4):467-75.

21. Mureşan M, Bancu S, Bara T, Bancu L, Turcu M, Mureşan S. Local recurrence after the sphincter-saving operations and abdominal perineal resection in rectal cancer. Chirurgia 2009;104(4):415-8.

22. Neagoe RM, Sala D, Voidazan S, Bancu S, Kiss L, Suciu H. Transthoracic versus transhiatal esophagectomy: a permanent dilemma. Our 15-year experience. Chirurgia. 2013;108(6):7807.

23. Schmidt SC, Strauch S, Rosch T. Management of esophageal perforations. Surg. Endosc. 2010;24(11):2809-13.

24. Kluge J. Acute and chronic mediastinitis. Chirurg.2016;87(6):469-77.

25. Abbas G, Schuchert MJ, Pettiford BL, et al. Contemporaneous management of esophageal perforation. Surgery. 2009;146(4):749-55.

26. Muresan M, Muresan S, Brinzaniuc K, et al. How much does decompressive laparotomy reduce the mortality rate in primary abdominal compartment syndrome? A single-centre prospective study on 66 patients. Medicine. 2017;96(5):e6006.

27. Wahed S, Dent B, Jones R, Griffin SM. The spectrum of oesophageal perforations and their influence on management. Br J Surg. 2014;101:e156-62.

28. Hermansson M, Johansson J, Gudbjartsson T, et al. Esophageal perforation in the south of Sweden: results of surgical treatment in 125 consecutive patients. BMC Surg. 2010;10:31.

29. Engelman R, Shahian D, Shemin R et al. The Society of Thoracic Surgeons Practice Guideline Series: Antibiotic Prophylaxis in Cardiac Surgery, Part II: Antibiotic Choice. Ann Thorac Surg 2007;83:1569-76.

30. Lazar HL, Ketchedjian A, Haime M, Karlson K, Cabral H. Topical vancomycin in combination with perioperative antibiotics and tight glycemic control helps to eliminate sternal wound infections. J Thorac Cardiovasc Surg. 2014;148:1035-40.

31. Foldyna B, Mueller M, Etz CD et al. Computed tomography improves the differentiation of infectious mediastinitis from normal postoperative changes after sternotomy in cardiac surgery. Eur Radiol. 2019;doi:10.1007/s00330-018-5946-5.

32. Gimenez A, Franquet T, Erasmus J, et al. Thoracic complications
The Journal of Critical Care Medicine 2019;5(2) • 55

of oesophageal disorders. Radiographics. 2002;22:S247-58.

33. Søreide JA, Viste A. Esophageal perforation: diagnostic workup and clinical decision-making in the first 24 hours. Scand J Trauma Resusc Emerg Med. 2011;19:66.

34. Nguyen VX, Nguyen CC, Nguyen BD. Multimodality imaging of oesophageal perforation by a wire bristle. Radiol Case Rep. 2015;5(1):364.

35. Burns PB, Rohrich RJ, Chung KC. The levels of evidence and their role in evidence-based medicine. Plast Reconstr Surg. 2011;128(1):305-310.

36. Sepesi B, Raymond DP, Peters JH. Esophageal perforation: surgical, endoscopic and medical management strategies. Curr Opin Gastroenterol. 2010;26:379-83.

37. Neagoe RM, Mureșan M, Bancu S, et al. Results of Laparoscopic Sleeve Gastrectomy-5-Year Follow-Up Study in an Eastern European Emerging Bariatric Center. Obes Surg. 2017;27(4):983-9.

38. Abu-Omar Y, Kocher GJ, Bosco P, et al. European Association for Cardio-Thoracic Surgery expert consensus statement on the prevention and management of mediastinitis. Eur J Cardiothorac Surg. 2017;51(1):10-29.

39. Petzina R, Hoffmann J, Navasardyan A et al. Negative pressure wound therapy for post-sternotomy mediastinitis reduces mortality rate and sternal re-infection rate compared to conventional treatment. Eur J Cardiothorac Surg. 2010;38:1102.

40. Glass GE, Murphy GF, Esmaeili A, Lai LM, Nanchahal J. Systematic review of the molecular mechanism of action of negative-pressure wound therapy. Br J Surg. 2014;101:162736.

41. Mureșan M, Mureșan S, Brinzaniuc K, Sala D, Neagoe RM. Negative Pressure Wound Therapy of Open Abdomen and Definitive Closure Techniques After Decompressive Laparotomy: A Single-center Observational Prospective Study. Wounds. 2018;30(10):310-6.

42. Krüger M, Decker S, Schneider JP et al. Surgical treatment of acute mediastinitis. Chirurg. 2016;87(6):478-85.

43. Huu Vinh V, Viet Dang Quang N, Van Khoi N. Surgical management of oesophageal perforation: role of primary closure. Asian Cardiovasc Thorac Ann. 2019;27(3):192-8.

44. Puerta Vicente A, Priego Jiménez P, Cornejo López MÁ et al. Management of Esophageal Perforation: 28-Year Experience in a Major Referral Center. Am Surg. 2018;84(5):684-9. 